This is an author-produced PDF of a published article. The publisher-authenticated version is available online, copyright Taylor \& Frances. Citation information for that definitive

version is:

Grant. C. (2016). Socio-economic concerns of young musicians of traditional genres in Cambodia: Implications for music sustainability, Ethnomusicology Forum, 25(3), 306-325, DOI: 10.1080/17411912.2016.1236696

\title{
Socio-economic concerns of young musicians of traditional genres in Cambodia: Implications for music sustainability
}

\author{
Catherine Grant
}

Recent work in applied ethnomusicology attempts to explain the dynamics of music endangerment and sustainability across global contexts. Building on these efforts, this article explores the relationships between the socioeconomic circumstances of young musicians of traditional Cambodian genres, and the sustainability of those genres. Interviews with four young musicians illustrate some of the complex ways in which socioeconomic concerns impact the maintenance and revitalisation of traditional musical practices in Cambodia. Many of these practices remain highly endangered, due to both the massive social and cultural disruption of the Khmer Rouge era and the ongoing socioeconomic and political challenges since that time. The article concludes with recommendations on supporting the livelihoods of young musicians in contemporary Cambodia, as well as developing more effective strategies to support the viable future of that country's traditional music.

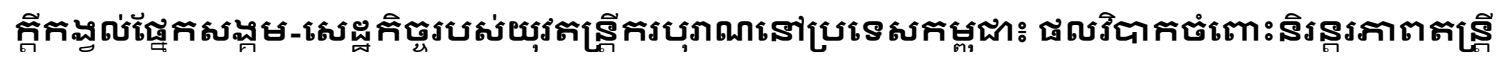
Catherine Grant

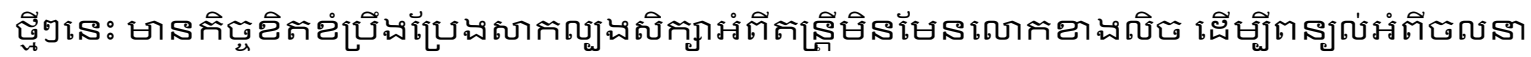

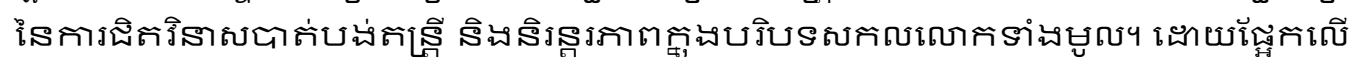

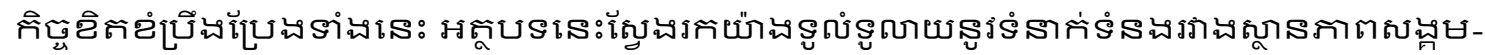

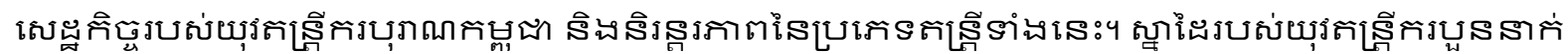

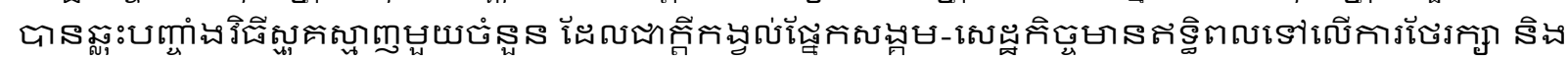
กางเนิ่

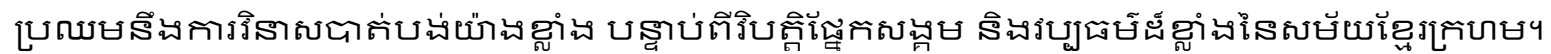

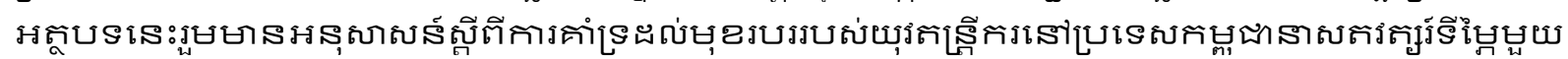

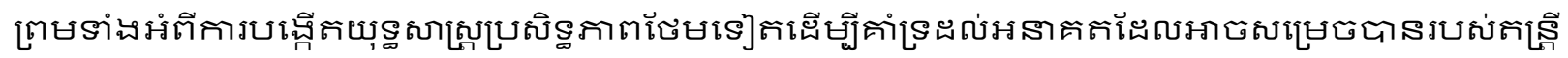

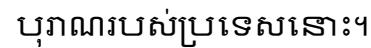

\section{Keywords}

Cambodia; Cultural Sustainability; Music Sustainability; Poverty; Traditional Music

Catherine Grant is Lecturer in Music Literature, Queensland Conservatorium Griffith University, and author of Music Endangerment: How Language Maintenance can Help (Oxford University Press 2014). She is recipient of an Australian national Future Justice medal for her advocacy and activism on issues of music endangerment and sustainability. Correspondence to: Catherine Grant, Griffith University, PO Box 3428, South Brisbane, QLD, 4101, Australia. Email: catherine.grant@ griffith.edu.au 
During visits to Cambodia in 2013 and 2014, I interviewed students, teachers and performers about their motivations for engaging with traditional Cambodian music, and the barriers and challenges that they faced. ${ }^{1}$ Nearly all the younger people told me that they viewed musical skills as a potential source of income, and that this was an incentive for them to learn. However, many also felt that their socioeconomic circumstances were a significant barrier to greater involvement with traditional music. Regular paid employment was necessary to support themselves or their families; household duties, work and study left little time for activities perceived to be nonessential, like learning or playing music; and instruments were expensive (Grant 2014b; 2015). This present research represents an attempt to better understand the relationship between the sustainability of traditional music genres in Cambodia, many of them currently in a precarious state, and the socioeconomic concerns of the young musicians who will determine their future. I explore how music sustainability efforts intersect with the socioeconomic situation of young people, and in turn, how that socioeconomic situation affects young people's efforts to engage with traditional music.

A 'second wave' of applied ethnomusicological research in the last few years (Harrison 2014; see also Pettan and Titon 2015) has been hallmarked by interest in the themes of music sustainability (e.g. Harrison, Mackinlay and Pettan 2010; Grant 2014a, b; Schippers \& Grant in press) and social justice, including poverty (e.g. Harrison 2013a). Various studies have explored intersections between music, poverty, civic participation, and skills development in specific contexts and among particular demographic groups (including people with disability, ethnic minorities, and women). However, few have examined at any length the relationship between music sustainability and the socioeconomic situation of musicians, where the latter is understood in Dutton and Levine's tripartite sense of status of income, of education, and of occupation (1989; see also Harrison 2013c). Exceptions include Titon (2008-2015), who notes that music sustainability means not only ensuring the viability of music traditions themselves, but also the livelihoods of musicians; Fiol (2013), who explores what he terms 'cultural and musical poverty' in Uttarakhand (India) and its relationship to socioeconomic change; and Moisala (2013), who examines the interplay of music, poverty, social deprivation and cultural rights of Gāine/Gandharva musicians of Nepal.

A few studies report on practical government or non-government initiatives with twin objectives in cultural sustainability and socioeconomic improvement. Drani (2014) describes the important role of NGOs in preserving and promoting intangible expressions of culture in Uganda, with concomitant socioeconomic outcomes. Bhattacharya reports on the 'Art for Life' project in West Bengal (eastern India), initiated in 2004, which worked with thousands of traditional performing and visual artists to develop 'an eco-system for revival and rejuvenation of traditional art skills as livelihood' (2014: 341). This project reportedly led to 'improved opportunity to

\footnotetext{
${ }^{1}$ As in earlier publications, in this paper I define traditional music in the Cambodian context as 'heritage' music genres from before the Khmer Rouge era (that is, pre-1975). The designation is arguably relatively unambiguous, given historical circumstances of cultural disruption and recent attempts to revive those genres largely as they were before the genocide. In the late 1990s, Sam, Roongruang and Nguyễn wrote of a 'fundamental division' between traditional and modern music styles and genres in Cambodia (1998, 155-156). Such a division arguably still exists, though in some areas of artistic activity it has begun to break down. This is partly due to the processes of 'reinventing' rather than restoring or reconstructing artistic practices (Ledgerwood, Ebihara \& Mortland, 1994, 5); but arguably an even greater consideration is the change and innovation in traditional artistic practices due to the shifting contexts and functions for traditional music necessitated by a fast-changing contemporary Cambodia. I explore these issues of maintaining and transforming traditional music in Grant (in press).
} 
perform, improved income from performance, lower average age of artists with the young taking interest, rejuvenation of the skill transmission systems, increased number of artists groups practicing and performing together and greater awareness on [sic] the art forms' (Bhattacharya 2014: 341). In Cambodia, the key project in this area is Capacity building and professionalization of Cambodian performing arts sector towards a sustainable cultural industry (2014-2017), financially supported by the European Commission and led by a consortium of NGOs. It assists performing artists to develop and manage their own sustainable, income-generating projects and enterprises. Projects like these that employ traditional music and the other arts in the service of socioeconomic benefit align with a 'capabilities approach' (Sen 1985; Nussbaum 2011), in that they help individuals 'become aware of their potential to gain more power and to change their living conditions' with the ambition 'to reinforce human dignity and social justice' (Auclair 2015: 36).

After providing a brief historical, social, and cultural background to Cambodia, I turn to consider the intersection between socioeconomic and cultural concerns for traditional performing artists in Cambodia. I draw on published scholarly, media, and organisational sources, as well as eight months' fieldwork in Cambodia between February 2013 and December 2015. During this fieldwork, I conducted interviews and conversations with over fifty traditional musicians, students, teachers and masters, exploring issues including personal engagement with traditional music, challenges and barriers to such engagement, and the endangerment and revitalisation of traditional genres. While this article is deeply informed by the findings of this broader research (reported in Grant 2014b, 2015, in press; Grant and Chuuon in press), here I centre on vignettes of just four individuals whose life experiences particularly shed light on the close and complex link between the socioeconomic concerns of musicians and the sustainability of traditional music genres in contemporary Cambodia.

\section{Rehabilitation and Transformation: Cambodia into the $21^{\text {st }}$ Century}

In the last half-century, Cambodia has undergone profound disruption and transformation. In the 1950s and into the 1960s, it was a self-sufficient, prosperous country whose capital city, Phnom Penh, was known for its vibrant rock music, grandiose architecture, and lively film scene. Political circumstances shifted quickly, and in the late 1960s, Cambodia faced civil war. Heavy bombing by US forces as part of the Vietnam War led to massive loss of life. The situation deteriorated even further in April 1975, when the Khmer Rouge seized control. The nation suffered nearly four years of Pol Pot's heinous rule, a purported effort to restore Cambodia to an agrarian classless state that left up to a quarter of the population dead and the remainder facing displacement, disease, famine, and trauma. Following another decade of civil war in the 1980s under Vietnamese occupation, the Paris Peace Accord of 1991 and Cambodia's first general elections in 1993 (overseen by the United Nations Transitional Authority) brought some semblance of normality to Cambodia, notwithstanding ongoing political problems and a violent political coup in 1997. Although significant progress has been made in rebuilding the country, considerable political, economic, and social challenges remain.

On certain socioeconomic indicators, the progress is clear. Although Cambodia remains the second-poorest country in Southeast Asia (ADB 2014b), poverty (in the sense of lacking minimum financial and living standards) has fallen considerably in the last decade, from over $50 \%$ to under $20 \%$ of the population of 15.4 million (NIS 2012; UNDP 2013; UNICEF 2015; World Bank 2015). Literacy is relatively high (around 87\%), and the average life expectancy is 71. The economy has grown fast over the last decade, due particularly to strong garment 
manufacture, tourism, agriculture, and construction industries (ADB 2014b). Cambodia has begun taking an active role in regional affairs and is signatory to several international conventions (including the 2003 UNESCO Convention on the Urgent Safeguarding of Intangible Cultural Heritage), and its government professes strong commitment to socioeconomic rehabilitation, sustainable development, and poverty reduction (Royal Government of Cambodia 2013). With per-capita income at around USD1000 (World Bank 2015; UNICEF 2015), Cambodia is now hovering between the status of a lower and lower middle-income country.

On other indicators, Cambodia performs considerably less well. Many people remain only marginally above the poverty line, and are highly vulnerable to falling back below it (World Bank 2015). One medical doctor serves every 4,500 people; almost $30 \%$ of the population lack access to safe drinking water, and 63\% have no sanitation facilities (ADB 2014b). Income, gender, and urban-rural disparities are marked (ABD 2014b); girls and women are disadvantaged in access to education; and women are significantly underrepresented in employment, and typically earn less than their male counterparts with similar education and experience (UNDP 2013). Though mobile phones are very widespread, only $6 \%$ of the population uses the internet (2013 figures, in UNICEF 2015), with consequences for education, health, and commercial capacity. Environmental problems, such as heavy waterway pollution, threaten livelihoods and food security; this is particularly true for the four in five Cambodians living rurally, most of whom still earn their subsistence through agriculture (UNDP 2013; NIS 2015). In many rural areas, the power supply is still absent or unreliable (I write this on battery power, in a village just a few kilometres from the northern township of Siem Riep). The $10 \%$ of non-Khmers resident in Cambodia (ADB 2014b), particularly ethnic minority populations in border areas, contend with frequent land-grabbing, deforestation and unwanted development, entailing loss of livelihood and lifestyles, and eventually, culture. In terms of education, in 2012 (the most recent available data), only $11 \%$ of women and $22 \%$ of men aged 25 and over had completed secondary education (MoYES 2014). Mean years of schooling lies at just 5.8 (UNDP, 2013), and tertiary enrolment is the lowest of any ASEAN country (Madhur 2014).

A significant proportion of the Cambodian population, artists and musicians being no exception, encounters or experiences poverty in their daily lives (NIS 2015, UNDP 2013). Harrison summarises various qualitative dimensions for conceptualising and measuring poverty (2013b: 5), including absolute poverty, referring to a level of basic subsistence; primary poverty, where an individual is unable to provide basic necessities for themselves or their families; secondary poverty, referring to situations minimally above the poverty line with vulnerability to falling below it; relative deprivation, when individuals and their families lack resources that are customary or encouraged in their societies; social exclusion, an inability to participate in 'normal' cultural, social, and economic activities; and livelihood sustainability, referring to a lack of sustainability and security in livelihood. All these are clearly present, even omnipresent, in Cambodian society. So too are cultural and musical poverty - the lack or reduction of the means to express music and culture (Fiol 2013) - due to the massive human and cultural disruption of the 1970s and 1980s combined with compounding contemporary factors, as described in the next section.

\section{Traditional Performing Arts in Cambodia}

From some angles, the Cambodian cultural sector appears vibrant enough. Several Cambodian performers and groups have established national and international reputations, from Kong Nay, 
elderly master of the traditional chapei, to rap duo CS and Yung Tee based in Long Beach, California. A number of performing arts organisations, including Sophiline Arts Ensemble, Amrita Performing Arts, and Sovanna Phum Art Association, have firmly established themselves in the arts landscape. New groups continue to spring up, like New Cambodian Artists (comprising young women dancers in Siem Riep) and the Community of Living Chapey (a troupe of chapei instrumentalists and singers in Phnom Penh); some are experimenting with a heady mix of traditional local genres and contemporary styles from Cambodia and abroad. Various culturalsector NGOs offer training programs in traditional and contemporary performing arts, both in the capital Phnom Penh (Champey Arts Academy, Apsara Arts Association, Cambodian Living Arts) and in provincial centres such as Kampot (Kampot Traditional Music School), Siem Riep (Cambodian Living Arts), and Battambang (Phare Ponleu Selpak). Action seems to be afoot at the government level too: in late 2014 the Ministry of Culture and Fine Arts launched Cambodia's first cultural policy, which professes government support and action in areas of arts education, creative industries, and cultural sustainability.

Despite these promising signs, as well as considerable community and non-government sector efforts to protect and promote traditional art forms since the devastating circumstances of the 1970s and 1980s, the viability of many traditional performing arts forms in Cambodia is still precarious. An estimated $90 \%$ of all artists lost their lives during the Khmer Rouge regime (Sam in Sam, Roongruang, and Nguyễn 1998: 209), and perhaps half of all traditional art forms were lost during that time (Visiting Arts 2001: 13); those with deep knowledge of traditional genres are nowadays very few in number; they are also elderly and some are in poor health. The challenges created by this limited knowledge base for traditional arts are compounded by rapid processes of social and technological change, urbanisation, and modernisation (Douglas 2009), the minimal presence of traditional arts in formal education (Sam 2007, 2008; Kallio and Partti 2013, Kallio and Westerlund 2015), and complex socioeconomic challenges that form the focus of this research. UNESCO attributes the threat of disappearance of intangible cultural expressions in Cambodia to 'long-lasting conflicts, the declining number of performers and the clear tendency among the younger generation to cultural influences from outside the country' (2007, para. 1). While the mere existence of the first cultural policy is certainly an advance, it remains to be seen whether policy will translate into action. Kallio and Westerlund perceive the overall situation of Cambodian arts serious enough to warrant the term 'cultural crisis' (2015: 2).

\section{Being a Traditional Performing Artist}

Not only traditional Cambodian music genres, but also the people who practice them face challenges. Like around two thirds of the population at large (UNDP 2013), the majority of Cambodian artists are under 30 years old, and many are still receiving training in the arts. Perhaps partly for this reason, their artistic activity is arguably characterised by 'informal practices and weak organisation' (CLA 2014: 2). A recent survey of over 450 performing artists and arts workers across theatre, music, circus, and dance forms, and in both rural and urban areas, revealed a common theme of irregular and inadequate employment, as well as discrepancies in income depending on geographic location (rural artists earn less per hour than their urban counterparts) and gender (female artists earn less than males) (CLA 2014). This survey also revealed the important role of non-profit organisations in the training and subsequent employment of artists: around a quarter of artists surveyed work regularly with at least one such organisation (CLA 2014: 2).

The following brief vignettes of four young Cambodian musicians - two male and two 
female, two based in urban Phnom Penh and two in the rural north, all under the age of 30broadly illustrate some of the links between the socioeconomic circumstances of young people and their involvement in traditional music. ${ }^{2}$ Each vignette displays indicators of poverty against one or more of the indicators outlined above (most obviously, vulnerability in terms of livelihood sustainability, as well as secondary poverty and relative deprivation). All these individuals are, or have been, involved with the activities of the non-profit organisation Cambodian Living Arts, which collaborates with artists and their communities to safeguard and revitalise traditional performing arts, with aspirations for concomitant social outcomes such as youth skills development, capacity-building and social empowerment. ${ }^{3}$ Only very brief information is provided here on genres and instruments, due to space limitations; the reader is referred to UNESCO (2003), Sam et al (1998), and Grant (2014b) for further description.

\section{SreyNy}

SreyNy (female) sings smot, a form of Cambodian Buddhist chant found across ritual ceremonial contexts and particularly associated with end-of-life events. Texts are in Khmer and Pali, the ritual language of Theravada Buddhism, and typically refer to the Buddha's life and teachings. According to many I spoke with during fieldwork, the association of smot with death and dying has given rise to some degree of fear of the genre among the general population.

I am 22 years old. I was born in Kampong Speu province, the fourth child of six. My parents are rice farmers, and my father was also a military physician. I think he received his education before the Khmer Rouge era. Although he never learnt music, he loves it, and when I was young he taught me some popular Cambodian songs from the 1960s. I loved singing those old songs. I decided I wanted to be an artist when I was about 9 or 10. Two of my older siblings had started learning smot at a nearby class, which was supported by an NGO. Sometimes they sang smot at home. At first I didn't like it because I was afraid of it, but when they taught me that it wasn't really about ghosts, but more to educate people to be grateful to our parents and ancestors, then I began to love it. Eventually I joined the smot class too.

Sometimes, when I was young, I lost hope about being a singer, because I thought, I'm poor, not beautiful, and I don't have white skin, so maybe I'm not fit to be an artist. But when I was in secondary school I won a little competition by singing, and that restored my hope. When I finished high school, my smot teacher wanted me to continue my smot studies. My father only wanted my older brother to study at university level, but my brother didn't want to. So when I said I wanted to study further, my father said I could if I also got a job to support myself at the same time. But I managed to get a scholarship through an arts NGO, which pays my university fees and a living stipend. Now I'm in my final year of a Bachelor of English in Phnom Penh. I live in the house of a distant cousin of mine, who is providing for me while I'm studying. There

\footnotetext{
${ }^{2}$ Semi-structured narrative interviews between two and four hours in duration, conducted in September and October 2015, form the basis for these vignettes. They were conducted in English and Khmer, with the assistance of a professional translator. The four musicians provided feedback on earlier versions of these vignettes, which has been incorporated into the condensed versions presented here. Two interviewees ('Socheat' and 'Davi') chose to use pseudonyms.

${ }^{3}$ In reality, few young musicians of traditional genres in Cambodia forge careers in the performing arts entirely outside of the NGO sphere, especially given the lack of school-based music education, which leaves NGOs as the primary locus for learning and teaching the traditional arts (CLA 2014). For this reason, the selection here of four musicians that all have prior or current connections, in various ways, with an NGO may therefore be considered broadly representative.
} 
are about ten people living in the house.

Because I don't have to pay rent, I could live off my stipend, but I also try to earn money in other ways, so that I have more to support my family. I used to teach an hour a week at an NGO, but now that organisation doesn't teach arts any more. I also used to perform at the National Museum shows. For three years, I performed twice every week, and got $\$ 10$ (USD) a show. But now the performances have stopped. I feel sad about that because we won't be able to show foreigners and other people our traditional arts, and it also means we artists cannot earn as much money. Some performers in those shows might stop being artists now, because they can't support themselves. I have one friend who performed in those shows who has quit her performing arts degree in order to open a small grocery store.

So I recently lost these two sources of income, but I can still earn money from singing smot at Buddhist ceremonies. I probably smot ${ }^{4}$ eight or ten times a month. Sometimes the monks call me up and invite me to go and smot at these ceremonies. Usually I receive $\$ 20$ to $\$ 30$ for these performances. I also have two private smot students, but they don't come regularly. Also, I sing classical wedding music at receptions. During high wedding season between October and mid-year, I might sing five to ten times per month. The ceremonies go from 7 am to noon, and I get paid \$20 to \$25-lower than for smot, but sometimes there is a bonus from the organiser. There are challenges in this work. The receptions are long, and we have to do promotional performances to reception managers and the public in order to attract work. And it's just irregular, seasonal work in any case.

I really want to be successful in supporting myself as an artist, but I'm still trying to figure out how. This is why I'm planning to set up a business when I finish university, offering packages of services for weddings and other ceremonies - music, but also hair, make-up and other services. I have three other people planning to invest with me, including my sister and her husband. I strongly believe we can be successful in this business operation. I can already smot, but I will need some other skills to manage this business. Even though we expect just to operate the business within Cambodia, I think that my studying English for business, tourism and management will help me in this venture.

So far I'm the only one in my family who has gone to university. My eldest brother is a farmer, and the second eldest is a factory worker. At first my parents didn't want me to be an artist. They said girls could not be artists, and that it would mean I wouldn't make a good living in the future. They also said that when girls get involved with the arts, they can get themselves a bad reputation by giving bad favours in return for money and other things. But now my parents understand the kinds of music I am involved in, and see my successes, and they are happy about me being a singer.

I think it is more difficult for traditional artists to earn a living than for contemporary artists. For smot, it is really difficult. A lot of people in the provinces are really afraid of smot, so I think there's more opportunity for me to establish my business here in Phnom Penh. People are a bit more knowledgeable about what smot means here; also, I can earn more money for a smot ceremony. But I want to provide my services free of charge in rural areas, because I know that people there are poor, and I still want them to have smot even if they can't afford it. I don't know what will happen in the future, but I'm sure I won't have to depend on my family financially. I already support them a little. My father is getting older now and is not so well, and he can't afford to put my younger brother through university. I want to do that. My brother is in grade 10 and

\footnotetext{
4 'Smot' is used both as a noun and a verb.
} 
wants to be a doctor. I think that's a good plan, because then he will be able to look after our family. He is very musical, although he's never learnt music. In his free time, he always makes a racket with buckets and pots. We have three or four cows for working in the rice fields, and when my brother goes to tend them, he sings along the way.

\section{Socheat}

Socheat (male) is a musician of kantaomming (also kontoaming or kantoam ming), a traditional ensemble genre used in funeral ceremonies in his province of Siem Riep to guide the spirit of the deceased into the afterlife. In recounting his story, Socheat also refers to another traditional ensemble genre, pinn peat (also pinpeat), which is considerably more widespread, and is played at ceremonial and celebratory occasions across Cambodia. The pinn peat ensemble is a little larger than that of kantaomming, comprising eight to ten instruments (mostly wind and percussion). An important feature is the sralai, a quadruple reed instrument played in both the kantaomming and pinn peat ensembles.

I'm 28 years old, and I'm from a village in Siem Riep province. I am a child of my father's first wife, the second of five brothers. Since my mother died, my father has had another five children. My parents were not musicians, and there was no music in our home. Sometimes I heard musicians playing in our village, and I was curious, but I didn't have the opportunity to learn music then.

My father is a rice farmer, and grows vegetables to sell in the market. Only one of my brothers finished primary school, because my father needed our help in the fields. Three of them work as construction workers now, and the other is married with a child and works in Thailand. I finished Grade 4 in school and then quit, because my father needed my help too. I was sad about that, because I liked school and wanted to learn.

Our family didn't get to visit my grandfather much as a child, because he lived in another village. But when I was 17 , an NGO contacted my grandfather about teaching a kantaomming class. I was surprised to learn he was a master musician, and I wanted to learn from him. I joined his class, along with one of my brothers, and learnt sralai. The NGO gave us a stipend of $\$ 8$ a month to attend the classes. After I had a studied kantoamming for a couple of years with my grandfather, the NGO encouraged me to return to school, using the money I'd received from their stipend and that I earned through performing. I felt so happy. I went back into Grade 5, and finally finished Grade 12 last year, but I didn't pass my last exams. I've applied to do more classes this year, and I will try the exams again next year. Even though I didn't pass, I'm still really happy that I've studied more. My education has helped me learn more about my country and the world, and I've learnt some English and can speak with foreigners now. It was challenging, though, being an older student, especially because I'm shy. A few others in Grade 12 were in their 20s, but at age 27, I was the oldest.

For the last few years, I've been responsible for liaising with clients and arranging the performances for my grandfather's kantaomming troupe. I made a name card to give to funeral service organisations around the commune, and to anyone else who is interested. It's also my responsibility to secure the musicians who will perform at each event, and this is a real challenge, because most musicians do some other kind of work, and our performances are very unpredictable and always at short notice because they're for funerals. It's also a problem because I am the only sralai player in the commune now - another one quit, and my grandfather is too old to play now - and we need sralai for kantaomming. So I have to play at every performance, 
but I'm very busy and have schoolwork to do too.

Recently, because my grandfather is old now and his health is not so good, I've started taking over the teaching responsibilities in the troupe. Sometimes when I'm busy performing or studying, I have to cancel the class. The troupe's very small now, just four or five students. Some members left because they were busy working or studying, and weren't getting a lot of performance opportunities anyway. At most we perform twice a month, for funerals all around Siem Riep province, but in some months we aren't required to play at all. We make around $\$ 50$ to $\$ 70$ per performance, starting in the afternoon and going into the night, and we share this money between us. I tried to encourage everyone to stay in the troupe because kantaomming is important, and not a lot of people know how to play it, but they left anyway.

After I began studying kantaomming with my grandfather, I also decided to learn pinn peat from another master in my own village, because I thought it could help me to earn more money later on. Now I sometimes perform pinn peat too, once or twice a month. That's irregular too, but there are more chances to perform pinn peat than kantaomming. From November to about February we might perform three or four times a month, and in low season, about once a month. We perform for festivals and many other special occasions. For an event with a small troupe, around five people, we might get around $\$ 120$ to $\$ 150$, which we divide up between us. We often start in the afternoon and play into the night, and then again from early in the morning. For some events, like the 15-day Pchum Ben festival that's on now, we play for free, just putting out a donation box in the pagoda. We used to play kantaomming for Pchum Ben too, but not any more, because many villagers think kantaomming should only be played when someone dies; they don't want to hear it at other times.

To help me earn more money as an artist, I want to learn marketing, communication, and general management skills. Maybe I could study at university in Siem Riep. I'd like to learn some other genres too, and how to write music notation. I want to create some professional resources for the pinn peat and kantaomming troupes, like costumes. I also want to build a little stage for us so that when clients hire us to play, we can sit down in a proper place, higher than normal, to be more professional. Now we just sit on a mat on the ground.

It's hard to earn enough money as a musician. I really want to try to make a living in this way, but if I find another job with better income and more financial stability, I might hand over my teaching responsibilities. I could still continue to perform. Performing kantaomming can only be a secondary job, because it's so irregular and people don't support it much anyway. For pinn peat, there are more performance opportunities, but also more competition from other troupes. If musicians can't earn enough money to support themselves and their families, and if there are few performance opportunities, maybe these traditions will be lost in the future. So it's important that Cambodian people value traditional music, because if they don't, artists don't get work. We need to help people understand more about these traditions.

I still live with my father and brothers in the house where I grew up, and I still help out in the rice fields. Someday I'd like to travel, but only if I can do so as a performer, otherwise I'd get out of practice. If I hadn't become a musician, I'd probably be a construction worker now, like my brothers. Music has helped me a lot. When I earn money from my performances, I give it to my father and grandfather, so I think they are happy I'm a musician too. My grandfather is very passionate about the future of kantaomming, and I share this passion. Kantaomming is very rare and I want to keep it strong for the next generation, like my grandfather has done. I want to do justice to his kindness in teaching me and his other students, and his commitment to this art 
form. I don't want to disappoint him.

\section{Davi}

Davi (female) plays several traditional instruments. In her account, she mentions tro khmer, a bowed three-string instrument used in several ensemble genres; the relatively rare kse diev ('one string'), a plucked monochord with gourd resonator, played in the 'areak' ensemble and also performed solo; skor, a type of drum; pei or (or pey ar), a reed instrument with cylindrical bore; and the chapei dong weng, a long-necked two-stringed strummed instrument played solo, duo, and in certain ensembles. Although all these instruments have recently been used in crosscultural, cross-genre experimental explorations (see, for example, the work of 'Krom Monster'; (http://www.theincidental.com/krom-monster), Davi's music-making follows strongly the tradition of her father. He is master of pleng kar boran (also plein ka boran), 'classical wedding music', an ensemble and vocal genre performed during sometimes days-long wedding ceremonies.

I am 27 years old, and come from a village in Siem Riep province. I am the tenth of eleven siblings, six girls and five boys, though one of my brothers died. When I was growing up, my parents used to grow vegetables and sell them in the markets. My mother and I also wove little baskets to sell. My father worked as a musician too, though back then he used to be paid in rice, not money. He can play tro khmer, chapei dong weng, skor and pei or. He also makes all those instruments, and sralai and kse diev too. I help him make skor, but I'm afraid of the electric tools he uses to make the others, so I leave those to him.

Normally, Cambodian children start primary school at about age 6, and finish at about age 12 . But I began at about age 14 or 15 , because my family couldn't afford to pay the 100 riel $^{5}$ per day for me to attend. Before starting school, I worked as a labourer in the rice fields like all my other brothers and sisters. My family doesn't own any fields: we were hired out to do work for others. Only one of my siblings finished primary school-my brother went right up to Grade 11. I got to Grade 6, but I was sick during the final exams, and when I recovered, I felt I should go back to the fields to earn money like my siblings. I was about 20 at that time. I felt very upset and disappointed that I couldn't finish primary school.

Growing up, all my siblings were interested in classical wedding music because they heard my grandfather and father play it. My father and my grandfather both knew how to play modern wedding music too, but they never did, because they were afraid of losing the classical tradition. My grandfather passed away when I was still young, and he was about 60. My father encouraged most of my brothers to learn the classical wedding music instruments, but not me, because I was a girl. When I asked him whether I could learn an instrument, he told me it would be better if I just learned to drum, or sing. But when I was about 16, my father met Arn Chorn Pond ${ }^{6}$ and Bong Arn encouraged my father to teach me instruments. So my father finally agreed, and I started to learn tro khmer. I was so happy. Now I am the only girl who plays tro khmer in Siem Riep province. I play kse diev too, and there is only one other girl in the province who plays it. For two years, I also studied chapei with Master Kong Nai-I went to live in his home in Kampot town. I wanted to learn chapei because it's mostly played by men who are blind or

\footnotetext{
${ }^{5} 100$ riel $=2$ or 3 cents (USD) (current rates).

${ }^{6}$ Arn Chorn-Pond is a key advocate of the traditional music revitalization efforts in Cambodia, and founder of the NGO Cambodian Living Arts. His life is the subject of the 2003 documentary The Flute Player (Jocelyn Glatzer) and the novel Never Fall Down (Patricia McCormick).
} 
disabled - it's rare for girls or women to play - and I wanted to prove that anyone could play chapei. In Kampot I missed my family a lot, especially when it rained, because at home in my village when it rained we always used to play music and sing together.

After I'd learnt to perform classical wedding music, I began to play in my father's group, which has about six to eight members. I receive 30,000 or 40,000 $\mathrm{riel}^{7}$ per performance, but we have to be at the ceremony a whole day and night, so it's very tiring. I also earn about 20,000 riel, sometimes more, performing kse diev in a show for tourists organised by an NGO. We've already performed many times in Siem Riep and other provinces, but recently there haven't been any performances. I don't know why. These are my two sources of income. I used to teach tro khmer, but most students dropped out because they found the instrument too difficult. I loved teaching. My dream is to be a music teacher. I want to teach at our house, like my father. He is very happy about that, and has given me some teaching responsibilities already. Sometimes he listens to me teaching or playing, even without me knowing, and then will give me advice on how to manage my students, or how to improve my tone quality when I play.

I want to go back to school but I feel that at my age it might be too late. I want to learn more skills. I'm learning how to use computers with the help of an NGO, and I've asked my friend to teach me English, though she doesn't have much time. I thought if I learn some English basics, perhaps I'd have enough knowledge to go back to school and be able to keep up. I'd like to learn about sales and marketing, to help promote the music groups I'm involved with. And if I learn some other skills like wedding make-up, I could link them with my classical wedding music skills. Probably to learn all those other things I need more money, so for now I'll concentrate on learning more classical wedding music skills. There are still some instruments that I don't know how to play, for example.

It's difficult to earn a living from traditional music, but I want to try. I know that one possibility for musicians is to earn some money performing, but to do other work too. For example, one old grandfather I know performs and teaches areak music, but he also earns money cleaning the pagoda. ${ }^{8}$ Even if I can't earn a lot through my music, I'm happy to do it. Music is like medicine. People who are sick, stressed, or unhappy can feel better and even heal themselves by listening to music. This is my own experience. When my mother died three years ago, I was very sad. I didn't want to do anything. One day I decided to pick up my instruments again, and playing them really helped me to feel better. I love playing music. Once when my mother was still alive, I was sick at home on an intravenous drip, and I knew there was a performance going on. My mother tried to stop me, but I didn't listen: I took out the drip and went to play, and when I came home I just reattached the drip.

Now I live with just my father, youngest brother, and nephew. Eight of my siblings still live in our village, like me, and the other one is not far away. My father still teaches music, though he's not so well now. Because my father and grandfather passed on their skills to me, I feel responsible for passing on my skills too, so that classical wedding music will continue in the future. Traditional musicians work hard to learn, practice, and perform. They often take time away from farming and work to sit and play music together. I think that these traditions, even the rare ones that don't have much support from villagers, will survive. A lot of outsiders, people

\footnotetext{
${ }^{7}$ Roughly $\$ 7.50$ to $\$ 10$ (USD).

${ }^{8}$ Areak is a ritual performance genre associated with spirit possession. Within a few weeks of our interview, Davi had secured a part-time job cleaning the office of a local arts NGO with which she is involved.
} 
from the rest of the world, support our traditional music, so I'm optimistic about its future.

\section{Panith}

Like Davi, Panith (male) plays several instruments, foremost the kse diev (see above). In his account, he also mentions the khloy, a relatively popular bamboo flute, typically played solo. Panith's grandfather, 90-year old Sok Duch, is a UNESCO-designated 'Living Human Treasure' for his musical and instrument-making knowledge and skills; he is considered the last living master of the kse diev.

I was born in 1989 in a village in Kandal province, the youngest of four children. My first exposure to music was through my grandfather. However, he lived quite far away in Takeo province, and my family and I rarely visited, so I didn't have much chance to play or learn music when I was young.

Most children in our village didn't go to school, because they couldn't afford it. We didn't have a school in our village, and the road to the next village was long and bumpy. Most of us couldn't afford bicycles. But my mother was a teacher, and she encouraged me to walk the four or five kilometres with her to the school across the rice fields so I could get an education. My father couldn't read or write. He was alcoholic, and committed domestic violence in our home, sometimes almost every day. But when he didn't drink, he was just a normal man, polite and modest, and he'd go fishing to get us food to eat.

Because of our poverty and the situation with my father, when I was about nine or ten my school principal offered my mother a room in the school for us to live in. We all moved in, including my father. My mother made and sold sweet desserts to the school children to support herself. My father didn't drink as much because he was away from his friends in the village, so we were relatively happy there. After about five years, my mother sold the old house and land in our village, and we all moved to my grandfather's house in Takeo province.

One day, some people from an NGO came to invite my grandfather to work with them to set up some classes teaching traditional music. He agreed, and started teaching a class of about 7 or 8 young people. I loved listening to those new sounds, and I wanted to learn too. But my grandfather didn't want to teach me: he said it was too hard to make a living as a musician, that it would mean I'd have poor living standards. But for me it wasn't about the money. I felt ashamed and embarrassed that everyone else was coming to learn from my grandfather, but what about me? Why wasn't I attending his class? After a while, when my grandfather saw how keen I was, he agreed I could learn. I started to learn kse diev, because I knew it was a difficult instrument to play and I wanted that challenge, and also because I saw my grandfather playing it. Since then, I've learnt to play many other instruments.

I graduated from secondary school in 2010. Unfortunately I didn't manage to get a university scholarship, because I didn't do well in my final exams. I couldn't afford to pay for university, so I took a short course in computer maintenance and repairs on weekends, travelling to Phnom Penh to do it. But I really wanted to go to university, and after a while I managed to get a half-scholarship, which was enough for me to be able to attend. I graduated last year with a major in English literature, though I still can't speak English very well.

These days, I only earn money through my music, and I do that in a few different ways. First, I teach kse diev, but I only have five regular students, who pay me around \$15 a month. Second, I also make kse diev instruments to sell. For each one I ask around $\$ 250$ to $\$ 300$, sometimes more for a really good quality one. This is a lot, but it is the real cost of my materials 
and my time. I let people pay in instalments. This year I've already sold two. Now I'm making one for a Khmer-American man living in the USA, who doesn't play kse diev but wants one anyway. Then, I earn $\$ 65$ per month performing kse diev solo at a big international hotel in Phnom Penh. I have a three-year contract there, and I play once a week for two hours. I sometimes also play classical wedding music at receptions, and I get about $\$ 40$ for that, sometimes more. This can be the easiest way to get work: when someone just calls me up to go and play at an event. Occasionally I might be asked to play kse diev or khloy for a recording that would then be used as sound track for a local production or show, and I might earn a bit of money from that too. I also made a recording with a traditional-contemporary band I'm in, and we sometimes earn a little money selling our CD album, or performing at charity or other events. But all together, this money is still not really enough. I still have difficulty earning enough.

My father, mother, and grandfather all still live together in Takeo province, and my siblings live nearby. My grandfather is very old now and not so well, and he doesn't teach any more. I don't go back to visit very often. When I left home to study in Phnom Penh, I was confident that I could improve my economic situation, but I haven't really succeeded, and I don't want my parents and grandfather to see my difficulties. I will visit them more often when I have more money. My father is a better man now, and my relationship with him has improved.

I can't see how I can have a regular income through music, so I don't believe it will be my career forever. It might be a bridge for me to move into another field - though I'm not sure which one - and then I'd just do music part time. The arts don't pay off like they should, considering all the effort that goes into being an artist. But I will never abandon music. It is my shadow. I want to share Cambodian traditional music with the rest of the world. I'd like to travel to other countries, maybe on a short-term scholarship somewhere to increase my knowledge about the arts. I want to continue to study English, and to learn Chinese too, because the Chinese have a strong artistic tradition; some traditional musicians there successfully earn a living from their skills, and by speaking Chinese I could learn about how they do that. Overall, my goal is to strengthen the arts sector in Cambodia, to find how to motivate other young people now and in the future to learn the arts. This will only happen when they can earn a living from their skills. I want to find the key to this, but I haven't found it yet.

\section{Socioeconomic Outcomes of Involvement in Traditional Performing Arts}

The potential of the arts to form a foundation, in various ways, for people-centred poverty alleviation strategies has been recently underscored in the international Declaration on the Inclusion of Culture in the Sustainable Development (IFACCA et al 2014). Probably the most obvious socioeconomic benefit for individuals of engaging with traditional music results when artists secure paid work and generate income through their artistic skills, as in the cases (to varying degrees) of all four young musicians represented above. But music and the arts offer pathways to improving individuals' socioeconomic circumstance in other ways too. One example is when the arts act as a driver or means to develop skills beyond the artistic. For SreyNy and Davi, for instance, their desire to make a living from traditional music provides the stimulus to (further) develop their English, computer, business management, and/or entrepreneurial skills. For the same reason, Panith wishes to improve his Chinese- and Englishlanguage skills.

Realising such aspirations may be difficult for these and other young musicians. Barriers include cost and access, particularly for those-like Davi and Socheat—who live rurally. Yet for those who do achieve them, the resulting skills may not only support music-related income 
generation, but also broaden career capacities and opportunities in other fields. Given the obvious challenges facing young Cambodians in securing sufficient paid work through traditional music activities (particularly for musicians of certain genres, like the funereal kantaomming, as Socheat observes), a pragmatic willingness to explore additional (or perhaps even alternative) job pathways, as well as the skills to succeed in them, may be essential. In this challenge of income generation and the need to explore 'portfolio careers', the situation of young Cambodian traditional musicians is not dissimilar from their peers in Western countries. The story of SreyNy's young friend who struggled to find performing work, and eventually quit her arts degree in order to work in a shop, would not sound unfamiliar to young musicians in many other parts of the world.

With the labour market in Cambodia characterised by a 'severe lacking [sic] of socioemotional skills and higher-order cognitive skills', including those relating to communication, multiple language proficiency, problem-solving, decision-making, teamwork, initiative, crosscultural understanding, and public speaking (Ngov, Kim and Heng 2015), the performing arts represent a pathway for developing the 'soft skills' many employers are looking for. For Socheat, for example, not only did his involvement in traditional music indirectly result in his returning to finish school (through the encouragement and financial support of the arts-based NGO that supported his music learning); it also provided him the opportunity to develop skills that now place him in a stronger position for future employment, whether within or outside of the arts sector. His ongoing leadership of the kantaomming troupe requires him to develop critical and creative thinking skills; problem-solving ability; learning skills (taking lessons from experience and applying them to his own learning and teaching); communication skills (including publicspeaking skills to share and promote his activities in schools and a local university); personal skills (like decision-making and self-management); and the social skills required for teamwork, troupe leadership, and relationship-building with other artists and clients (see Madhur 2014). Socheat's story, like those of the other three musicians represented in this article, also suggests that involvement in music may foster certain behavioural and attitudinal assets - among them, perseverance, commitment and self-discipline - that are desirable to employers.

By generating employment and income and serving as the stimulus for developing new artistic and non-artistic skills, involvement in music may help individuals to develop greater confidence and self-esteem, reduce anxiety and stress related to economic hardship or vulnerability, improve physical health and wellbeing, and foster personal relationships and participation in society (Harrison 2013c). Socheat's engagement with music, for example, led him to receive full schooling, lessening the social barriers that result from minimal education. Rather than being a 'construction worker or farmer', his music has offered him an alternative perspective on his life potential (and perhaps that of his family too, who he now helps support). SreyNy's early success singing in a competition revived her lagging self-esteem; her recounting of her plans to establish a smot business in the near future was characterised by enthusiasm and confidence. For Davi, playing music made her happy, and helped alleviate her grief following her mother's death; when she became sick, she disconnected herself from her intravenous drip to go to perform, because she felt that doing so would make her feel better. Whether this decision was primarily emotionally or financially motivated is, in one sense, inconsequential: for the socioeconomically disadvantaged, gaining income and occupational status indeed improves health and wellbeing (WHO 2008). 


\section{Implications for Music Sustainability}

As in many other contexts around the world, the relationship in Cambodia between socioeconomic concerns and the sustainability of traditional music is paradoxical on a number of counts. A vicious circle is easily discernible: performers find it hard to make a living from their skills, leaving little economic incentive to pursue the arts professionally; this further damps the vitality and viability of traditional genres. Widespread socioeconomic disadvantage, particularly outside the capital, is a further compounding factor. Should poverty be reduced, improvements might be expected (at least in theory) in the vitality and viability of musical practices, simply because the social and economic capacity of individual musicians and their communities to engage with those cultural practices would be strengthened. While claiming a direct link between improved socioeconomic circumstances and improved cultural vitality is too simplistic due to the myriad and complex factors affecting each, it is certainly fair to say that music sustainability closely intersects with socioeconomic concerns, and each can affect the other (Moisala 2013; Weintraub and Yung 2009).

That is one argument for approaching the urgent issue of music endangerment in Cambodia, and the wider 'cultural crisis' (Kallio and Westerlund 2015: 2) of which it is a part, from a broad poverty alleviation perspective. Aside from the challenges of engaging in learning, teaching or performing music when faced with more pressing material concerns, socioeconomic challenges can also make it difficult for artists to access the education, training and resources that may help them become more successful in their income-generating efforts. Opportunities for income generation through the performing arts in Cambodia are currently so limited and precarious that many aspiring traditional artists choose — or are forced - to abandon their artistic training for study or employment in other more lucrative fields. In Cambodia's current socioeconomic circumstances, and until or unless its traditional music (and performing arts more broadly) can offer more stable and adequate work opportunities (that is, greater 'livelihood sustainability'), a moral question arises for NGOs, government cultural agencies, and others concerned with cultural revitalisation: is it fair to encourage young people to devote their lives to trying to make a living as traditional musicians? Put another way: in what circumstances (if ever) should the sustainable future of the cultural heritage trump the sustainable future of the person? These questions suggest that caution is needed in the development rhetoric currently adopted by many arts NGOs in Cambodia; they also underscore the importance of problematising the aims and objectives of cultural sustainability interventions around the world.

Another angle from which to approach cultural revitalisation in Cambodia and elsewhereone that is being pursued through the earlier-mentioned NGO-consortium project Capacity building and professionalization of Cambodian performing arts sector towards a sustainable cultural industry (2014-2017) — is to focus directly upon building a stronger arts sector. With more opportunities in the creative industries for remunerated performance, young people could more easily view the traditional performing arts as a sustainable career option, and thus be more inclined to pursue or persist with training; this would also increase the demand for teaching and learning (see also Grant 2015). Thus, a stronger arts sector would seem very likely to benefit music revitalisation efforts, as well as improving the socioeconomic situation of musicians.

However, the existence of a vibrant and supportive arts sector is predicated on the existence of a public that first, values the traditional arts sufficiently to patronise them; and second, has the financial means to do so. Several Cambodian musicians who I spoke with, particularly in the provinces, regretted the growing tendency to broadcast audio recordings of classical wedding 
music and kantaomming at ceremonies, rather than hiring live performers. They attributed this tendency only partly to a lack of understanding of these genres, their meaning, and their value; the other reason, they believed, was the inability of community members to pay the artists a fair performance fee. In other contexts, various scholars have noted the significant challenge of trying to maintain musical and other cultural heritage in challenging social and economic situations. On the Indonesian island of Lombok, economic hardship has compelled some families and even whole villages to sell their sets of instruments or shadow puppets in order to buy food (Harnish in press); and Bhattacharya describes how over time, folk art practitioners in West Bengal stopped nurturing their traditions due 'poverty and lack of scope for performance and practice in [the] changing sociocultural environment', leading to loss of heritage and cultural diversity (2014: 344-345). In such cases, it seems that the social energy that might usually be directed toward creative or artistic pursuits is diverted to other, more pressing, things.

It might be expected, then, that traditional Cambodian artists would fare better in the capital city of Phnom Penh, where the growing middle class has disposable income (as SreyNy astutely notes). Yet a paradox presents itself here too: those residents of (increasingly consumer-driven and Westernised) Phnom Penh who are financially able to support the traditional arts may be precisely those unlikely to deeply understand their meaning or value. Particularly among urban youth, traditional genres - if they are known at all — can be seen as backward. The 'old' performing arts are out of step with new lifestyles and preferences for contemporary, mostly Western-influenced recreation and entertainment.

This situation, naturally enough, stimulates NGOs and other cultural sector stakeholders to explore possibilities for tailoring traditional art forms to suit the tastes of those most able to patronise it. This is the intent behind the 'Cambodian Living Arts On Stage' shows at the National Museum in Phnom Penh, presented for the entertainment of locals (for \$5 USD a show) and, somewhat more successfully, for tourists (\$15 USD). The perils that attend the creation of 'revised, sanitized, ahistorical, and somewhat folkorized traditional arts' (Harnish, in press) are extensively explored in the scholarly literature; those potentially resulting from the commoditisation of traditional arts include their devaluation, loss of context and meaning, and the reinforcement of a perceived distance and difference between 'urban' and 'rural' - or 'traditional' and 'modern' - cultural expressions. Furthermore, NGO projects that aim to stimulate the creative industries through building musical skills among individuals in poverty risk replicating socioeconomic status inequalities in those industries (Harrison 2013c). Harrison implies that those involved in organising such programs might critically reflect on "which socioeconomic categories of individuals actually benefit in terms of income, employment, and related education, and to what extent' (2013b: 10), a recommendation as prudent for the Cambodian context as it is for the very different Canadian context she describes.

Commoditising traditional arts is not ipso facto a bad thing, however, either for the sustainability of the traditions themselves or for the artists who produce and perform them. If former contexts and/or functions for these traditions are no longer sufficient for their viability, or for the economic viability of the artists, then exploring options for the commercial presentation of the art forms may be an appropriate, even necessary, strategy toward cultural sustainability. In this regard, the situation of traditional music genres in Cambodia resonates with Fiol's (2013) description of two discourses on culture: that of 'lack' - the perspective of culture as commodity, with potential for developing a vibrant, income-generating cultural industry — and that of 'loss', the perspective of culture as heritage, with potential for maintaining and revitalising traditions 
seen to be in danger of disappearing. As Fiol observes, the reconciliation of these two discourses can be challenging. In Cambodia, it seems that cultural revitalisation efforts based on either discourse are likely to be most effective if they unfold in tandem with broader strategies to improve the socioeconomic situation of individuals, their families and communities-most obviously, efforts toward poverty alleviation.

Ironically, the challenges of earning an income through the traditional performing arts in contemporary Cambodia may ultimately prove either a blessing or a curse for the future of that country's traditional music genres. The curse is obvious enough. But the creativity, innovation, and entrepreneurship needed to make a career from artistic skills are already, in some cases, flowing into similarly creative thought and practice in terms of exploring new performance contexts, functions, and modes for the traditional arts (Grant in press). The Community of Living Chapey, a dynamic young group, is exploring new performance contexts (such as festivals and hotels) and functions (such as media and tourist entertainment) for a music tradition (chapei) that, at the time of writing in late 2015, is under consideration for UNESCO's List of Intangible Cultural Heritage in Need of Urgent Safeguarding. I argue elsewhere that the openness of musicians (and their communities) to artistic flexibility, and their responsiveness to changes in the wider sociocultural environment, may be a key determinant in the sustainability of traditional genres in Cambodia, which may otherwise find themselves a fossilised museum piece with little relevance to the contemporary world (Grant in press). In this sense, a flexible attitude toward 'tradition' and 'authenticity' may well be essential for music sustainability.

If 'cultural rights' means a group's economic and social ability to sustain its cultural practices and transmit them to future generations (Moisala 2013), then in Cambodia, as in elsewhere in the world, cultural rights are clearly deeply interconnected with socioeconomic concerns. Limited economic capacity and resources - not only of musicians, but also of entire communities and indeed the nation itself - act as barriers to vibrant and viable traditional arts and arts practices. As the Cambodian government, applied researchers, NGOs and others continue to work with local musicians and communities to develop interventions in the urgent situation of Cambodian traditional music, this must be a foremost consideration.

\section{Acknowledgements}

My thanks to interpreters Sun Sopheak and Va Veasna, interpreting assistant Chap Vithur, administrative assistant Yon Sokhorn, and Cambodian Living Arts for organisational help in this research; also to Dr Irene S. Leung and anonymous reviewers for helpful comments on an earlier version of this article. Special thanks to all those artists who shared their stories, both those directly represented in this article and others I spoke with throughout my fieldwork.

\section{Funding}

This work was supported by a 2015 Endeavour Australia Cheung Kong Research Fellowship awarded by the Australian Government (grant number BR14-003378).

\section{References}

ADB (Asian Development Bank). 2014a. Asian Development Bank and Cambodia: Fact Sheet. Mandaluyong City, Philippines: Asian Development Bank. 2014b. Cambodia: Diversifying beyond Garments and Tourism. Mandaluyong City, Philippines: Asian Development Bank.

Auclair, Elizabeth. 2015. 'Ordinary Heritage, Participation and Social Cohesion: The suburbs of Paris'. In Theory 
and Practice in Heritage and Sustainability: Between Past and Future, edited by Elizabeth Auclair and Graham Fairclough, 25-39. Oxford, UK: Routledge.

Bhattacharya, Ananya. 2014. 'Integrating Culture in Planning and Action for Sustainable Development: The Role of ICH NGOs'. Volkskunde 3: 339-347.

CLA (Cambodian Living Arts). 2014. 'Training and Employment Needs Assessment on Cambodian Performing Arts Sector'. Phnom Penh, Cambodia: Cambodian Living Arts.

Douglas, Gavin. 2009. Music in Mainland Southeast Asia. New York: Oxford University Press.

Drani, Emily. 2014. 'The Role of NGOs in Preserving and Promoting Intangible Cultural Heritage in Uganda: The Cross-Cultural Foundation of Uganda'. Volkskunde 3: 405-409.

Dutton, D.B. and Levine, S. 1989. 'Overview, Methodological Critique, and Reformulation'. In Pathways to Health: The Role of Social Factors, edited by John Bunker, Deanna Gomby, and Barbara Kehrer, 29-69. Menlo Park, CA: Henry J. Kaiser Family Foundation.

Fiol, Stefan. 2013. 'Of Lack and Loss: Assessing Cultural and Musical Poverty in Uttarakhand'. Yearbook for Traditional Music 45: 83-96.

Grant, Catherine. 2014a. Music Endangerment: How Language Maintenance can Help. New York: Oxford University Press.

. 2014b. 'Perspectives of Culture-bearers on the Vitality, Viability and Value of Traditional Khmer Music Genres in Contemporary Cambodia'. Asia-Pacific Journal of Anthropology 15 (1): 26-46.

. 2015. 'Learning and Teaching Traditional Music in Cambodia: Challenges and Incentives'. International Journal of Music Education [Online First], 1-12: DOI: 10.1177/0255761415619394.

. In press. 'Finding New Ground: Maintaining and Transforming Traditional Music'. In Routledge

Handbook of Contemporary Cambodia, edited by Katherine Brickell and Simon Springer. New York:

Routledge.

Grant, Catherine and Chhuon Sarin. In press. 'Assessing the Vitality and Viability of Three Traditional Khmer Music Genres'. Yearbook for Traditional Music.

Harnish, David. In press. 'The Challenges of Music Sustainability in Lombok, Indonesia.' In Performing Indonesia, edited by Sumarsam and Andrew McGraw. Washington DC: Smithsonian Institution Scholarly Press.

Harrison, Klisala, ed. 2013a. Yearbook for Traditional Music, 45. Special edition: Music and Poverty. . 2013b. 'The Relationship of Poverty to Music'. Yearbook for Traditional Music, 45: 1-12. 2013c. 'Music, Health, and Socio-Economic Status: A Perspective on Urban Poverty in Canada'. Yearbook for Traditional Music 45: 58-73. . 2014. 'The Second Wave of Applied Ethnomusicology'. MUSICultures, 41 (2): 15-33.

Harrison, Klisala, Elizabeth Mackinlay and Svanibor Pettan, eds. 2010. Applied Ethnomusicology: Historical and Contemporary Approaches. Cambridge: Cambridge Scholars Publishing.

IFACCA et al. 2014. 'Declaration on the Inclusion of Culture in the Sustainable Development'. http://www.culture2015goal.net/index.php/home/declaration (accessed 17 November, 2015).

Kallio, Alexis Anja and Heidi Partti. 2013. 'Music Education for a Nation: Teaching Patriotic Ideas and Ideals in Global Societies'. Action for Change in Music Education 12 (3): 5-30.

Kallio, Alexis Anja and Heidi Westerlund. 2015. 'The Ethics of Survival: Teaching the Traditional Arts to Disadvantaged Children in Post-conflict Cambodia'. International Journal of Music Education 34 (1): 90103.

Ledgerwood, Judy, May M. Ebihara, and Carol A. Mortland. 1994. 'Introduction.' In MayM. Ebihara, Carol A. Mortland, and Judy Ledgerwood, eds., Cambodian culture since 1975: Homeland and exile, 1-26. Ithaca and London: Cornell University Press.

Madhur, Srinivasa. 2014. 'Cambodia's Skill Gap: An Anatomy of Issues and Policy Options '. Working Paper Series No. 98. Cambodia Development Research Institute: Phnom Penh. http://www.cdri.org.kh/webdata/download/wp/wp98e.pdf (accessed 26 September, 2015).

Moisala, Pirkko. 2013. "Nobody Should be Forced to make a Living by Begging”: Social Exclusion and Cultural Rights of Gāine/Gandharva Musicians of Nepal'. Yearbook of Traditional Music 45: 13-27.

MoYES (Ministry of Education, Youth and Sport). 2014. 'Education Statistics and Indicators 2013-2014'. Phnom Penh: Royal Government of Cambodia. http://www.moeys.gov.kh/en/emis/577.html\#.VfwPCrS_c0s (accessed 26 September, 2015).

NIS (National Institute of Statistics). 2015. 'Cambodia Socio-Economic Survey (CSES) Information'. Phnom Penh: Royal Government of Cambodia. http://www.nis.gov.kh/index.php/en/find-statistic/social- 
statistics/cses/cses-information.html (accessed 26 September, 2015).

Ngov, Penghuy, Kim Veara and Heng Molyaneth. 2015. 'Knowledge, Skills and Attitude: Implications of Cambodia Moving to Upper-middle-income Country'. Paper presented in the Cambodia Development Research Forum II. Sofitel Phnom Penh. 15 September.

Nussbaum, Martha. 2011. Creating Capabilities: The Human Development Approach. Cambridge, MA: Harvard University Press.

Pettan, Svanibor and Jeff Todd Titon, eds. 2015. The Oxford Handbook of Applied Ethnomusicology. New York: Oxford University Press.

Royal Government of Cambodia. 2013. 'Rectangular Strategy' for Growth, Employment, Equity and Efficiency: Phase III of the Royal Government of Cambodia of the Fifth Legislature of the National Assembly'. http://www.akp.gov.kh/?p=37179 (accessed 26 September, 2015).

Sam, Sam-Ang. 2007. 'Transmission of Khmer Traditional Performing arts: Its Genuineness, Challenge, and Impact on Society'. In Authenticity and cultural identity: Senri ethnological reports, 65: 123-136.

Sam, Sam-Ang. 2008. 'Arts Education in Cambodia: Its Social, Moral and Economic Impact.' In L. Joubert (Ed.), Educating in the arts: The Asian experience, Twenty-four essays, 83-99. The Netherlands: Springer.

Sam, Sam-Ang, Panya Roongruang, and Phong T. Nguyễn. 1998. 'The Khmer People.' In Garland encyclopaedia of world music Vol. 4: Southeast Asia, edited by Terry Miller. http://alexanderstreet.com (accessed 6 October, 2015).

Schippers, Huib and Catherine Grant, eds. in press. Sustainable Futures for Music Cultures: An Ecological Perspective. New York: Oxford University Press.

Sen, Amartya. 1985. Commodities and Capabilities. Amsterdam: North-Holland.

Titon, Jeff Todd. 2008-2015. 'Sustainable Music: A Research Blog on the Subject of Sustainability and Music'. http://sustainablemusic.blogspot.com (accessed 6 October, 2015).

UNESCO. 2003. 'Traditional Musical Instruments of Cambodia' ( $2^{\text {nd }}$ edition) http://unesdoc.unesco.org/images/0013/001352/135257mb.pdf (accessed 10 October, 2015).

UNESCO. 2007. 'Establishment of a Living Human Treasures System in the Kingdom of Cambodia'. http://portal.unesco.org/culture/en/ev.phpURL_ID=29180\&URL_DO=DO_TOPIC\&URL_SECTION=201.html (accessed 29 August, 2016).

UNICEF. 2015. 'Statistics: Cambodia'. http://www.unicef.org/infobycountry/cambodia_statistics.html (accessed 26 September, 2015).

UNDP (United Nations Development Programme). 2013. 'About Cambodia’. http://www.kh.undp.org/content/cambodia/en/home/countryinfo/ (accessed 26 September, 2015).

Visiting Arts. 2001. South East Asia Regional Arts Profile: Cambodia Arts Directory. London: Visiting Arts. Weintraub, Andrew, and Bell Yung. 2009, eds. Music and Cultural Rights. Urbana: University of Illinois Press.

World Bank. 2015. 'Cambodia'. Washington, DC: World Bank. http://data.worldbank.org/country/cambodia (accessed 26 September, 2015).

WHO (World Health Organisation). 2008. 'Closing the Gap in a Generation: Health Equity through Action on the Social Determinants of Health'. http://www.who.int/social determinants/thecommission/finalreport/en/ (accessed 11 October, 2015). 